\title{
Redes, atores e desenvolvimento rural: perspectivas na construção de uma abordagem relacional
}

CLAUDIA JOB SCHMITT"

\section{Resumo}

A construção de uma abordagem relacional, capaz de dar conta das complexas dinâmicas sociais que configuram o mundo rural contemporâneo, em sua diversidade, tem se constituído, sobretudo a partir da década de 80, como um desafio para as ciências sociais. Nessa direção, diferentes correntes interpretativas passaram a incorporar a noção de rede como ferramenta capaz de interligar atores, objetos, significados e práticas, no estudo dos processos de desenvolvimento rural. Este artigo busca explorar alguns dessas referências de análise, identificando elementos de convergência e pontos de descontinuidade entre diferentes perspectivas.

Palavras-chave: Desenvolvimento rural. Redes. Abordagem relacional. Teoria do Ator Rede.

\footnotetext{
* Doutora em Sociologia e Professora Adjunta do Programa de Pós-Graduação de Ciências Sociais em Desenvolvimento, Agricultura e Sociedade (CPDA) da Universidade Federal Rural do Rio de Janeiro (UFRRJ).
} 


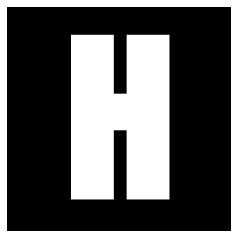

istoricamente, a palavra desenvolvimento tem operado como uma idéia-força, capaz de articular distintas constelações de atores, significados e práticas. Sua polissemia e plasticidade lhe asseguram a capacidade de transitar entre diferentes mundos: do mundo dos economistas ao universo das ciências humanas, das diretrizes das organizações multilaterais ao discurso dos movimentos sociais. Ao longo do tempo, vários qualificativos foram sendo acrescentados ao termo: desenvolvimento endógeno, desenvolvimento em escala humana, desenvolvimento sustentável, entre tantos outros, refletindo os inúmeros conflitos existentes na definição de valores, objetivos e metodologias de intervenção que a palavra busca mobilizar.

Este artigo não tem a pretensão de reconstituir a complexa trajetória da idéia de desenvolvimento através de distintas configurações históricas $^{1}$. Busca, fundamentalmente, refletir sobre as possíveis contribuições de uma abordagem relacional dos atores e de suas redes de interdependência, na análise dos processos de mudança social no rural contemporâneo. Evita-se, na medida do possível, uma visão do desenvolvimento como uma essência a ser descoberta ("o verdadeiro desenvolvimento") ou como um fenômeno regido por um conjunto previamente definido de estruturas, externas aos agentes sociais, cujo funcionamento precisaria ser decodificado pelo analista. Trata-se, acima de tudo, de organizar elementos de análise capazes de contribuir para um esforço de leitura e interpretação que visa abarcar: de um lado, os campos de relações articulados pela noção de desenvolvimento, em suas múltiplas dinâmicas de afirmação, tradução e contestação; de outro, os diferentes processos,

1 Uma visão histórica do processo de constituição do desenvolvimento como um campo de estudos, e de suas transformações ao longo do tempo, pode ser encontrada em autores como Leys (1996), Cooper e Packard (2005), entre outros. 
através dos quais, ordenamentos materiais e simbólicos que constituem a realidade social são instituídos, reproduzidos, contestados e transformados, nas interações que se estabelecem entre agentes sociais.

Concorda-se, em boa medida, com a argumentação apresentada por Escobar (1995; 2005;2010), de que a idéia de desenvolvimento remete a uma construção discursiva, temporal e espacialmente referenciada, que soube se afirmar, sobretudo a partir do fim da Segunda Guerra Mundial, como um regime de representação, através de um aparato internacionalizado de produção de conhecimento e de intervenção, ancorado em instituições como o Banco Mundial, as Nações Unidas, as agências bilaterais de desenvolvimento, as políticas implementadas pelos Estados Nacionais, bem como em um conjunto heterogêneo de organizações não governamentais (ONGs). Seria equivocado, nesse sentido, tratar desenvolvimento e mudança social como conceitos equivalentes, tendo em vista que diferentes formas de ser no mundo não se traduzem através de uma única episteme.

Entende-se, ao mesmo tempo, que a identificação do desenvolvimento como um dispositivo de saber e poder, capaz de se impor sobre outras formas de conhecimento e de forjar subjetividades, não esgota as possibilidades analíticas de enfrentamento dessa temática. Da mesma forma em que é preciso compreender os mecanismos que possibilitam a reprodução, ao longo do tempo e em diferentes espaços, de determinados padrões e ordenamentos, torna-se relevante, também, captar o caráter contingente e descontínuo dessas construções, analisando as dinâmicas sociais através das quais racionalidades, modelos e formas de organizar o mundo são mantidos, negociados, rejeitados ou re-apropriados. Resgata-se, nessa direção, a noção de rede, buscando explorar as possibilidades analíticas e interpretativas ensejadas por um enfoque relacional.

Este texto encontra-se organizado, fundamentalmente, em quatro seções. Em um primeiro momento, procura organizar algumas das prin- 
cipais questões envolvidas na formulação de uma abordagem relacional das políticas e práticas de desenvolvimento na perspectiva das ciências sociais. A segunda seção discute a noção de rede e sua utilização como uma ferramenta analítica nos estudos sobre o desenvolvimento rural, a partir de diferentes enfoques. Apresenta-se, a seguir, uma breve reflexão acerca das possibilidades heurísticas dessa noção no estudo das transformações do mundo rural na contemporaneidade.

\section{As abordagens relacionais nas ciências sociais}

Esta seção do trabalho busca refletir acerca das possíveis contribuições de uma perspectiva relacional para o estudo das políticas, práticas e interações sociais que têm como dimensão articuladora a idéia de desenvolvimento. Essa noção foi sendo construída, em uma trajetória histórica de afirmação e contestação, tendo sido tratada como discurso, como um conjunto de orientações para o desenho de projetos e políticas ou como forma de descrever um processo evolutivo de mudança social. O foco de análise selecionado concentra-se no desenvolvimento como campo temático de investigação. Mesmo reconhecendo o caráter multidisciplinar dos debates nessa área, mantém-se, aqui, um olhar referenciado nas ciências sociais, sabendo, no entanto, que a adoção de uma perspectiva relacional de análise dos fenômenos sociais tem implicações que transcendem as fronteiras estabelecidas entre diferentes disciplinas científicas.

Vale a pena lembrar que o esforço por romper com modos substancialistas de conhecimento do social já se faz presente desde o século XIX, em autores como Marx, Simmel, entre outros. Em Simmel, por exemplo, os grandes sistemas e organizações supra-individuais são vistos como uma consolidação das interações imediatas produzidas ao longo da vida dos indivíduos, não possuindo existência prévia em relação aos sujeitos so- 
ciais. A sociedade não se constitui como uma substância, algo concreto em si mesmo, mas como um acontecer. São os processos de sociação e não a sociedade, em si mesma, o foco privilegiado da análise (Simmel, 2002) (Wilkis y Berger, 2005).

Esse tipo de abordagem diferencia-se dos vários tipos de substancialismo que marcaram, e ainda marcam, o pensamento das ciências sociais em suas diferentes vertentes. Perspectiva esta que está presente tanto nas abordagens individualistas, a exemplo da teoria da escolha racional, como nas abordagens holistas, referenciadas em diferentes tipos de unidades pré-construídas: grupos, nações, sociedades, estruturas ou sistemas sociais. Em ambas, o social é visto como sendo constituído por entidades autorreguladas e autodeterminadas, tomadas como chave explicativa dos fenômenos sociais. Uma segunda vertente do substancialismo define os agentes sociais por suas características intrínsecas, descritas a partir de um conjunto diferenciado de atributos ou variáveis, cuja incidência, de forma isolada ou combinada, explica o comportamento das entidades analisadas (Emirbayer, 1997, p. 283-286).

As abordagens relacionais, em seus diversos matizes, têm como ponto em comum a ruptura com uma epistemologia baseada em unidades préconstruídas, sejam elas o indivíduo, a sociedade ou a cultura. Os atores sociais, suas características e dinâmicas de interação, só existem, efetivamente, como parte de uma teia de interdependências, impossível de ser apartada de seus contextos temporais e espaciais de existência. Colocamse, com isso, em questão, conceitos e pares de oposições fortemente imbricados na produção do discurso e nos métodos de investigação das ciências sociais, entre eles: estrutura/ação, macro/micro, sociedade/indivíduo.

No esforço por compreender seus objetos de estudo como campos de relações, respostas distintas foram sendo dadas por diferentes autores, informados por entendimentos variados em relação aos próprios fundamentos epistemológicos das ciências sociais. 
Destaca-se, por exemplo, no caso de Elias, uma forte preocupação em relação à transferência de termos e conceitos, cunhados no contexto das ciências naturais, para o léxico das ciências sociais (Elias, 1982, p.19). Pensar o social como uma trama de interdependências, para além da oposição indivíduo/sociedade, não significa atribuir à sociedade um tipo de causalidade semelhante à encontrada na natureza física (Elias, 1982, p. 67), conferindo-Ihe um determinismo ou uma legalidade exteriores a qualquer tipo de intencionalidade ou vontade humana. Os ordenamentos, formas de regulação e hierarquias que emergem no curso das interações sociais são resultado de processos abertos e interdependentes, que podem ser apreendidos, sobretudo, através do conceito de figuração. As figurações definemse como um modelo cambiante, constituído pelos atores como totalidade, onde os jogadores estão presentes não apenas com seu intelecto, mas com toda a sua pessoa, com todo o seu fazer, e com todas as suas omissões em suas relações mútuas (Elias, p. 1982, p. 57).

Na sociologia de Elias, o processo de construção de interdependências é tratado como um fenômeno dinâmico, relacionado à trajetória do indivíduo e ao seu processo de socialização. Nele, as pressões exercidas pelas redes de interdependência, que buscam forjar um indivíduo "típico de seu grupo social", são mediadas pela posição que ele ocupa nesse sistema de relações e pela trajetória singular percorrida ao longo de sua biografia. Os processos de socialização e de individuação encontram-se, por sua vez, inseridos em dinâmicas mais abrangentes de transformação, que provocam mudanças de longo prazo, tanto na estrutura das redes como na constituição psíquica e social dos próprios indivíduos (Letonturier, 2005).

Não se trata, aqui, de resgatar toda a diversidade de contribuições que, no campo das ciências sociais, adotaram uma perspectiva relacional como referência analítica. O que é importante destacar é que a incorporação desse tipo de enfoque ao estudo das políticas e práticas de desenvolvimento implica uma ruptura com perspectivas de análise e modos 
de explicação dos processos de mudança social centrados em unidades, sujeitos sociais ou circunscrições territoriais pré-estabelecidos - "o Estado", "as populações pobres", "as comunidades" -, colocando em tela os processos e campos de relações nos quais se constituem os objetivos, os quadros de referência e os próprios agentes do desenvolvimento. As fronteiras que demarcam os limites entre o global e o local, o convencional e o alternativo, o Estado e a sociedade civil, o econômico e o social, deixam de se constituir como mapas seguros de navegação, tornando-se, elas próprias, objeto de investigação.

A emergência, nas ciências sociais, de uma agenda de pesquisa mais sensível à heterogeneidade e particularidade das experiências de desenvolvimento, e, em boa medida, mais fortemente comprometida com uma análise voltada à perspectiva dos atores, não é um fato inteiramente novo, tendo tido seu início já na década de 80. Esse esforço de reconstrução de modos de explicação e estratégias de pesquisa buscava responder, entre outras coisas, a uma crescente dissociação entre a produção acadêmica e o "mundo real" das práticas e da ação², refletindo, também, as transformações que, com o advento do neoliberalismo, afetaram as geometrias de poder das políticas de desenvolvimento.

As expressões dessa "virada interpretativa" serão, sem dúvida, muito diferenciadas, não implicando, necessariamente, uma aproximação teórica ou metodológica com abordagens de tipo relacional. De modo geral, é possível identificar um repensar, ainda que em diferentes direções, acerca das relações existentes entre atores, estruturas e práticas sociais, com questionamentos importantes em relação a: (i) as possíveis vinculações a

2 Reproduzimos, aqui, em linhas gerais, a análise feita por Booth (1994) no livro Repensando o Desenvolvimento Social (Rethinking Social Development), acerca da emergência, na segunda metade da década de 80, dessa nova agenda de pesquisa. Este trabalho condensa um importante esforço de mapeamento, problematização e diálogo entre diferentes perspectivas de análise em debate nesse período. 
serem estabelecidas entre o esforço de reconhecimento da diversidade, multilinearidade e multidimensionalidade do desenvolvimento - acompanhada, frequentemente, de uma grande atenção para processos microssociais - e a construção de teorias e quadros explicativos para além do local; (ii) o estatuto teórico da noção de desenvolvimento como conceito ou categoria explicativa, frente às inúmeras críticas dirigidas a essa noção como parte de um projeto modernista (e de dominação); (iii) o caráter negociado e socialmente construído nas experiências da vida cotidiana e a disseminação e reprodução, em âmbito global, de modos de organização capazes de impor as "regras do jogo" nos mais diferentes contextos.

No caso específico dos estudos sobre o desenvolvimento rural, os debates nas últimas décadas foram revitalizados por novas abordagens teóricas e metodológicas, traduzidas em uma ampla gama de estudos de caso, análises comparativas, reflexões de natureza metodológica e esforços de teorização. Elegemos aqui, como fio condutor, no diálogo com essa literatura, a noção de rede e suas aplicações na análise e interpretação das políticas e práticas de desenvolvimento sob uma perspectiva relacional.

\section{Redes e atores nos estudos sobre o desenvolvimento rural: diferentes vertentes}

A noção de rede vem sendo utilizada, nas ciências sociais e nos estudos sobre o desenvolvimento, de múltiplas formas, tornando-se difícil, por vezes, precisar seu real significado e sua contribuição como ferramenta de análise. A imagem de um sistema composto por nós e fluxos é freqüentemente evocada como metáfora, no esforço por construir representações capazes de dar conta da complexidade do social.

Autores como Castells (1999) falam da emergência, na contemporaneidade, de uma sociedade em rede, capitalista, globalizada, regi- 
da por núcleos de poder descentralizados, e estruturada com base nas tecnologias da informação. As redes, sua arquitetura e suas dinâmicas de inclusão/exclusão, estariam na base dos processos e funções predominantes em nossa sociedade, dando origem a uma nova morfologia do social (Castells, 1999, p. 498).

Para além da rede como metáfora ou como matriz técnica, é possível identificar na literatura um conjunto de trabalhos que se utilizam na noção de rede como uma ferramenta analítica ou, como no caso da Teoria do Ator Rede, como base para a construção de uma nova ontologia do social ${ }^{3}$.

Verifica-se, por fim, uma crescente referência às redes como estrutura ou mecanismo de governança, capaz de integrar múltiplos "portadores de interesse" (stakeholders). A esses conjuntos articulados "em forma de rede", são conferidos, a priori, inúmeros atributos ou propriedades emergentes: flexibilidade, horizontalidade, cultura democrática, entre outros. Essa visão normativa e positiva das redes orienta, atualmente, inúmeros projetos de intervenção "pró-desenvolvimento", refletindo o lugar conquistado por essa noção no imaginário da sociedade capitalista contemporânea.

Mesmo correndo risco de simplificação, entende-se como sendo possível identificar três principais vertentes, por meio das quais a noção de rede vem adentrando a literatura sobre o desenvolvimento e, no que é o nosso foco principal, sobre o desenvolvimento rural: a perspectiva orientada aos atores, a Teoria do Ator Rede e a análise das redes sociais proposta pelos estudiosos da sociologia econômica. Para além dessas três linhas interpretativas, merece destaque o esforço coletivo de construção de uma abordagem integradora do desenvolvimento rural desenvolvido por diferentes pesquisadores no âmbito do programa ETUDE ${ }^{4}$ e sintetiza-

3 Uma detalhada discussão envolvendo a desconstrução da chamada "dimensão social" como um domínio da realidade, definido a priori, pode ser encontrada em Latour (2007).

4 Enlarging the Understanding of rural Development in Europe, ou seja, Ampliando a compreensão do Desenvolvimento rural na Europa. 
do nos livros Unfolding webs: the dynamics of regional rural development ${ }^{5}$ (Ploeg; Marsden, 2008) e Networking the rural: the future of green regions in Europe $^{6}$ (Milone e Ventura, 2010) que, em que pese a sua forte aproximação com a perspectiva orientada ao ator, também estabelecem um diálogo com outros enfoques sobre as redes.

Redes e agência na perspectiva orientada aos atores

A referência à noção de rede na abordagem conhecida como perspectiva orientada aos atores remete a um conjunto de autores clássicos da antropologia, incluindo Raddcliff-Brown, Mitchell, Barnes e Bott ${ }^{7}$, que se utilizaram dessa noção em estudos etnográficos ambientados em diferentes cenários, influenciando, de forma abrangente, o debate sobre esse tema nas ciências sociais. Embora esse conceito tenha sido assimilado, inicialmente, no pensamento de Raddcliff-Brown, a uma visão mais estática de estrutura (Raddcliff-Brown, 1989, p. 282), o mesmo foi posteriormente apropriado pelo movimento de crítica ao estrutural-funcionalismo, através da chamada Escola de Manchester. Conflito e poder tornam-se elementos inerentes ao processo de manutenção e transformação das estruturas sociais, em um enfoque em que a própria estrutura é percebida como uma rede de relações (Scott, 2000).

Esse modo de perceber os nexos existentes entre a ação social e as redes se encontra muito presente, por exemplo, nos trabalhos de Long (1992; 2007), bem como nos de outros autores também identificados à perspectiva orientada ao ator $^{8}$. Esse referencial procura, em linhas gerais,

5 Em português esse título poderia ser traduzido como "O desdobrar das redes: a dinâmica do desenvolvimento rural regional"

6 Uma tradução aproximada, em português, seria: "Interligando as redes do rural: o futuro das regiões verdes na Europa".

7 Ver: Raddcliff-Brown (1989); Mitchell (1974); Barnes (2010); Bott (1976 ).

8 A incorporação um enfoque relacional, orientado aos atores, encontra-se fortemente presente também nos trabalhos de Ploeg. Os vínculos das unidades produtivas familiares com os mercados foram analisados, com base em uma perspectiva relacional, no livro Trabalho, Mercados 
romper com as limitações impostas pelas abordagens macro-estruturais seja na versão liberal da teoria da modernização, seja na versão marxista -, que tendem a ver o desenvolvimento como efeito de "forças externas" aos agentes sociais. Parte-se do pressuposto de que, embora muitas mudanças estruturais sejam, de fato, resultado de "forças externas" (como o Estado, o mercado ou as políticas internacionais pró-desenvolvimento), as formas de intervenção só afetam as oportunidades sociais e a conduta dos indivíduos à medida que se introduzem em seus modos de vida, tomando forma, direta ou indiretamente, nas experiências do cotidiano (Long, 2007, p. 42). A perspectiva orientada aos atores visa, justamente, compreender o modo como distintos agentes influenciam a formulação e a implementação de políticas e projetos de desenvolvimento, afetando seus resultados.

A crítica à idéia de "intervenção planejada" e a ênfase na experiência social construída na vida cotidiana emergem como componentes de uma abordagem que busca apreender, com base em uma perspectiva construtivista, as maneiras intrincadas e variadas em que velhas e novas formas de produção, consumo, sustento e identidade se entrelaçam e geram modelos heterogêneos de mudança econômica e cultural (Long, 2007, p. 39).

A agência - associada à capacidade humana de conhecer e atuar - materializa-se tanto na articulação de cadeias de atores como na canalização de diferentes elementos (demandas, bens, instrumentos, informações), através de pontos nodais de interpretação e interação (Long, 2007, p. 50). As redes, mobilizando relações, recursos e significados, propiciam a interconexão entre diferentes mundos e formas de conhecimento, transcendendo domínios institucionais específicos e interligando uma grande diversidade de arenas. É na confluência entre essas múltiplas realidades,

e Produção Agrícola (Labor, Markets and Agricultural Production) - Ploeg (1990) - tendo como ancoragem diferentes estudos de caso. Referências à noção de rede podem ser encontradas em Ploeg et al. (2000); Ploeg (2008) e Ploeg e Marsden (2008). 
e através de processos de luta, negociação e acomodação, em diferentes campos de batalha, que se constrói o desenvolvimento.

Como referencial de pesquisa empírica, a perspectiva orientada ao ator gerou uma ampla gama de trabalhos, ao quais tomam, como objeto de investigação, as múltiplas interfaces estabelecidas pelas políticas e ações voltadas à promoção do desenvolvimento, em diferentes regiões do mundo, influenciando, também, a produção brasileira recente ${ }^{9}$.

\section{A associação entre "humanos" $\mathrm{e}$ " não-humanos" e a emergência do Ator-Rede}

A Teoria do Ator Rede (ANT - no acrônimo em inglês, Actor-Network Theory) foi desenvolvida a partir do final dos anos 70, por autores como Law, Latour, Callon, entre outros, sobretudo através de análises voltadas à ciência e à tecnologia. Para os autores identificados com essa abordagem, as redes não correspondem, como propõe Castells (1999, p. 505) a uma nova morfologia do social. Na verdade, a própria referência a uma morfologia, como uma estrutura geradora de determinados processos sociais, parece ser avessa a esse enfoque. O ponto de partida da análise não é a ordem instituída mas, sim, os processos plurais e incompletos através dos quais a ordem é construída. Trata-se, aqui, nas palavras de Law, de uma sociologia de verbos e não de uma sociologia de nomes (Law 1994, p. 15). Noções como nível, camada, território, estrutura, sistema, entre outras, largamente empregadas no campo das ciências sociais, não são compreendidas como determinações, que estariam "por trás" dos processos empíricos analisados. De acordo com o princípio metodológico da simetria, todos os elementos

9 Ver, por exemplo: Schneider (2006) e Schneider e Niederle (2010), bem como os diferentes trabalhos produzidos no âmbito do Projeto Sementes e Brotos da Transição. Inovação, Poder e Desenvolvimento em Áreas Rurais do Brasil. Ver: http://www6.ufrgs.br/pgdr/ipode/projeto. htm. Consultado em: janeiro de 2011. 
que constituem uma cadeia de associações precisam ser explicados, sem nenhuma distinção prévia entre o social e o natural, o micro e o macro, as causas e os efeitos. Toda e qualquer forma de ordenamento é um produto da atividade performativa e recursiva das redes.

Como observa Latour, a rede, na ANT, funciona como uma ferramenta que permite seguir determinadas cadeias de tradução. Não pode ser confundida, portanto, com um objeto "em forma de rede", a ser descrito pelo pesquisador (Latour, 2007, p. 131). A essa concepção de rede, encontra-se associada uma visão muito específica da agência e dos atores. Para a ANT, o ator não é uma fonte de ação, seja ele um indivíduo, um grupo ou uma organização (Latour, 2007, p. 46). Ele só existe através de um conjunto de associações, estabelecidas entre agentes "humanos" e "não-humanos", conectados entre si por meio de diferentes processos de tradução. As relações de poder, a conformação de centros de cálculo com capacidade de agir à longa distância, a "estabilização" de determinadas conexões através da formação de "caixas pretas" tornam-se foco de atenção, em cuidadosos trabalhos de cunho etnográfico, bem como em diversos textos de natureza teórica ${ }^{10}$.

Um dos pontos mais controvertidos da ANT é, justamente, o fato de que, nessa perspectiva, os elementos do mundo material não são apenas mobilizados pelos seres humanos, mas participam, efetivamente, da ação. É na imbricação entre o social e o material que as sociedades humanas estabilizam, no tempo e no espaço, determinadas conexões, cristalizadas em configurações sociais e materiais cada vez mais complexas (Murdoch, 1997). Um objeto ou um ser humano pode atuar como intermediário ou como um mediador, dependendo da cadeia de associações estabelecida

10 Uma ampla lista de indicações de leitura relacionadas à ANT pode ser encontrada no banco de referências organizado por Law. Ver: <http://www.lancs.ac.uk/fass/centres/css/ant/ant. htm >. Consultado em: janeiro de 2011. 
em cada situação" ${ }^{11}$ A ação, tanto dos "humanos" como dos "não-humanos", é uma propriedade emergente das redes, que humanizam aquilo que chamamos de objetos e "coisificam" o que chamamos de seres humanos, dando origem a inúmeros híbridos dificilmente classificáveis, seja no mundo das pessoas, seja no mundo das coisas.

A ANT foi incorporada, de diferentes maneiras, aos estudos agroalimentares, rurais e regionais, como um enfoque alternativo aos estudos mais clássicos da economia sobre cadeias de commodities, sistemas de provisão, ou às abordagens mais "convencionais" sobre as tecnologias na agricultura. Como observa Wilkinson (2006), a persistência do movimento contra os transgênicos, as expressões de vulnerabilidade das cadeias agroalimentares frente à ação de "não-humanos" (príons, vírus ou bactérias) causadores de doenças de origem alimentar, a expansão do mercado de orgânicos, entre outros processos emergentes, ampliaram o interesse de diferentes pesquisadores frente a uma abordagem que busca romper com a separação sociedade-natureza, que marca as ciências sociais desde a sua origem.

Um outro elemento a ser destacado, e que parece ter contribuído para fortalecer a aproximação estabelecida entre a ANT e a produção acadêmica relacionada à agricultura e ao mundo rural, refere-se à forma como o conceito de rede, nos termos propostos pela ANT, influencia a percepção do espaço como uma dimensão analítica, possibilitando uma nova leitura das relações que se estabelecem entre o local e o global, as redes e o território, o agrícola e o rural. Nos termos propostos pela ANT, a dimensão espacial deixa de ser tratada como uma moldura, no interior da qual se desenvolve a ação social. A ação das redes constrói também o

11 Para Latour, um intermediário é um elemento que não se transforma no decorrer da ação. Um mediador, transforma, traduz, distorce, modifica o sentido ou os elementos por ele carregados. (Latour, 2007, p. 390). 
espaço, que passa a ser compreendido, cada vez mais, como um espaço político - componente estratégico na produção, reprodução e transformação de distintas formas de ordenamento da realidade (Murdoch, 1998) (Murdoch, 2000) (Dicken et al., 2001).

A ANT tornou-se uma referência importante na análise de "redes agroalimentares alternativas" como, por exemplo, as redes de comércio justo (Whatmore e Thorne, 1997), influenciando, também no Brasil, diversos trabalhos de pesquisa empírica relacionados a esse tema (Schmitt, 2001; Mior, 2005; Pinheiro, 2010).

Redes sociais e ação econômica no estudo do desenvolvimento rural

Uma terceira vertente de aplicação da noção de rede nos estudos sobre o desenvolvimento rural remete às discussões travadas no âmbito da sociologia econômica, acerca das relações entre processos econômicos e estruturas sociais. A inserção social das ações econômicas coloca-se, aqui, no centro da análise, traduzida através do conceito de imbricação (embededdness), desenvolvido inicialmente por Polanyi e, posteriormente, por Granovetter (Granovetter, 1992; 2005) ${ }^{12}$. A idéia de imbricação encontra-se ancorada, na sociologia de Granovetter, em três pressupostos básicos: (i) a ação econômica é uma forma de ação

12 É importante destacar que o rico debate que vem sendo travado, no campo da sociologia econômica, focalizando as redes, os mercados, os atores e as instituições econômicas, mobiliza uma pluralidade de enfoques, em um diálogo marcado por convergências, controvérsias, aproximações e esforços de demarcação de fronteiras. Diferenças existentes entre a abordagem de Granovetter e uma visão dos mercados mais estreitamente vinculada à proposta da ANT foram demarcadas, por exemplo, por Callon (1997). Uma análise detalhada das interfaces estabelecidas entre distintas vertentes de interpretação sobre as redes no campo dos estudos agroalimentares pode ser encontrada em Wilkinson (2006). 
social; (ii) a ação econômica é socialmente situada e, (iii) as instituições econômicas são construções sociais.

Nos trabalhos do autor, a noção de rede, definida, fundamentalmente, como um conjunto regular de contatos ou conexões similares entre indivíduos ou grupos (Swedberg e Granovetter, 1992, p. 9), aparece frequentemente associada à idéia de estrutura. Para Granovetter, nenhum fenômeno social pode ser analisado, sem que seja considerada sua imersão em redes de relações sociais (Granovetter, 1990, p. 15). A análise de redes sociais não é, portanto, apenas um método. Define-se, também, como um enfoque analítico, que busca se contrapor tanto à visão sobressocializada da vida social, característica, por exemplo, do estrutural-funcionalismo, como à visão subssocializada da ação econômica, presente na economia neoclássica. O comportamento individual não se constrói, nem como o resultado da internalização de um sistema pré-estabelecido de normas e papéis, nem como expressão do cálculo racional do homo economicus. Os indivíduos estão vinculados a múltiplas redes, regidas por princípios econômicos e não econômicos que influenciam, de diferentes maneiras, as suas ações. As redes se constituem, nessa ótica, como uma chave de leitura capaz de desvendar os contextos relacionais onde se inserem os atores: indivíduos, famílias, grupos e organizações. São, portanto, fundamentalmente, sociais.

Atenção especial é atribuída, nesse enfoque, aos padrões de interação que se estabelecem, no âmbito das redes, aos tipos de vínculos estabelecidos e à posição dos indivíduos na estrutura reticular. Verifica-se, aqui, a forte vinculação de Granovetter com a análise de redes sociais na forma como esse programa de pesquisas se desenvolveu nos Estados Unidos, sobretudo a partir da década de 70, com ampla utilização de representações gráficas e medidas quantitativas de descrição e comparação entre redes. 
A influência das redes sociais sobre os resultados econômicos se dá de diferentes maneiras: alterando o fluxo e a qualidade da informação; favorecendo a mobilização de recursos; institucionalizando mecanismos de retribuição ou de punição; possibilitando a estruturação (ou desestruturação) de vínculos confiança. Estes vínculos são construídos, por sua vez, tanto por meio de relações interpessoais (laços fortes) como através dos chamados laços fracos, que ligam agentes socialmente distantes, possibilitando uma aproximação entre universos sociais distintos (Granovetter, 1973). Aspectos relacionados à estrutura das redes, como, por exemplo, sua densidade, influenciam diretamente a estruturação de sistemas compartilhados de normas e referências, que incidem, por sua vez, de diferentes maneiras, sobre as atividades econômicas.

Mas, o papel atribuído às redes na sociologia econômica de Granovetter abre caminho para uma série de interrogações, sinalizadas por diferentes autores engajados nesse debate. A metáfora da imbricação foi criticada, por exemplo, por Callon, a partir de um enfoque referenciado na ANT (1999). O caráter impreciso do conceito de imbricação foi também criticado por Fliegstein, quando discute a criação de mercados estáveis como um processo político (Fliegstein, 1996). Emerge, nesse diálogo, a tensão entre a rede tomada como um tipo de estrutura social, subjacente à ação econômica, e as redes (incluindo, aí, os mercados) como cadeia de associações estruturadas a partir de relações de poder e processos de agenciamento. Na crítica de Callon, aparece, mais uma vez, a importância das associações entre "humanos" e "não-humanos" na constituição dos mercados como dispositivos de cálculo (Callon, 1999).

A influência dos debates sobre redes sociais, mercados e formas de organização econômica, tanto na perspectiva proposta por Granovetter como através de outros referenciais de interpretação, encontra-se presente, de diferentes maneiras, nos estudos sobre o desenvolvimento 
rural. As relações de parentesco, amizade e proximidade, bem como as características do ambiente cultural em que se estruturam as atividades econômicas, foram constituídas como objetos de investigação, informando diferentes estudos sobre o desenvolvimento local ou territorial, bem como análises centradas em cadeias específicas de produção ${ }^{13}$. Em oposição a uma visão unidirecional dos processos de mercantilização da vida social, presente, ainda que de forma distinta, nos clássicos da questão agrária, emerge um olhar sensível, de um lado, à diversidade de formas econômicas, arranjos institucionais e interconexões entre o rural e o urbano constitutivas dos territórios; de outro, às oportunidades ensejadas pelas redes no que tange à mobilização de recursos e de capacidades locais, com frequentes referências ao conceito de capital social.

Da mesma forma, verifica-se um crescente interesse em relação às novas possibilidades de imbricação entre redes, valores, produtos e territórios, surgidas no contexto de uma economia de qualidade, em que as preferências dos consumidores em relação a alimentos saudáveis, seguros ou ecologicamente produzidos abrem novas potencialidades na construção de mercados diferenciados, através de redes com capacidade de operação à longa distância (como o comércio justo) ou dos chamados circuitos curtos de comercialização ${ }^{14}$.

As redes na construção de uma abordagem integrada do desenvolvimento das regiões rurais

Como já foi sinalizado anteriormente, um esforço importante de construção de um referencial integrado de análise do desenvolvimento

13 Influências dessa abordagem no estudo do rural brasileiro podem ser encontradas, por exemplo, em: Radomsky e Schneider (2007) e Abramovay (2007).

14 Para uma discussão desse tema no âmbito da sociologia econômica ver: Wilkinson, (2003/2008). 
rural, tendo como referência o contexto europeu, pode ser encontrado no trabalho de pesquisa e reflexão teórica desenvolvido no âmbito do programa $E_{T U D E}{ }^{15}$. Os resultados gerados por essa iniciativa foram reunidos em duas publicações: Unfolding webs: the dynamics of regional rural development, livro organizado por Ploeg e Marsden (2008), e Networking the rural: the future of green regions in Europe, uma coletânea de artigos organizada por Milone e Ventura (2010). As atividades implementadas no âmbito desta proposta interdisciplinar de investigação envolveram pesquisadores de diferentes países da Europa, mobilizando um amplo universo de experiências de desenvolvimento rural (63 casos), ambientadas em diferentes regiões do continente.

$\mathrm{Na}$ formulação proposta pelos autores, as redes são incorporadas, simultaneamente, como um instrumento de análise, capaz de possibilitar o estudo das transformações do espaço rural na contemporaneidade, e como parte de um referencial teórico e metodológico voltado à implementação de políticas e capaz de orientar estratégias sustentáveis de desenvolvimento rural.

No marco de interpretação construído ao longo dos diferentes artigos/ capítulos que compõe o trabalho, as redes que conformam as sociedades e as economias rurais surgem da combinação entre diferentes elementos (atores, setores, recursos, lugares e atividades) que, em sua articulação, dão origem a distintas trajetórias de desenvolvimento, bem como a formas extremamente diversificadas de configuração do espaço rural.

A região emerge, aqui, como um nível estratégico de análise, na construção de uma nova teoria do desenvolvimento rural, centrada não apenas nas atividades agrícolas mas na multifuncionalidade dos espaços

15 ETUDE significa Enlarging the understanding of rural development in Europe, em português, Ampliando a compreensão do desenvolvimento rural na Europa. Participaram dessa iniciativa pesquisadores provenientes de seis diferentes países da Europa. 
rurais. Os autores partem de uma definição positiva do espaço rural, baseada, fundamentalmente, em três elementos distintivos, a saber: (i) o rural, em suas diferentes configurações e atividades, é identificado como lugar de co-produção entre os seres humanos e a natureza; (ii) o rural é caracterizado, também, em termos relativos, como ambiente onde predominam pequenas e médias empresas; (iii) por fim, identifica-se, nas áreas rurais, uma presença mais forte de mecanismos não-mercantis de intercâmbio, o que contribui para que essas regiões consigam manter uma certa resiliência frente às oscilações do mercado.

No plano teórico, as redes podem ser analisadas com base na intersecção entre diferentes dimensões: endogeneidade, produção de novidades, sustentabilidade, capital social, arranjos institucionais e a governança dos mercados. A articulação existente entre esses diferentes elementos tem o potencial de se traduzir tanto na força como na fragilidade das regiões rurais. Redes, coerência ${ }^{16}$ e capital territorial, em sua articulação com as dimensões anteriormente propostas (endogeneidade, sustentabilidade, entre outras), tornam-se componentes chave no fortalecimento da rede rural como conjunto mais ou menos coerente de recursos, atores, atividades, conexões e externalidades positivas, capaz de fortalecer e dar suporte a processos sustentáveis de desenvolvimento rural.

Segundo Horlings e Marsden (2010), as redes se constituem, no modelo analítico proposto pelos pesquisadores do programa ETUDE, como um recurso heurístico, que permite "fotografar" as distintas configurações assumidas pelas dimensões analíticas acima mencionadas, em processos regionalmente situados de desenvolvimento rural. O caminho de inves-

16 A coerência pode ser percebida como sendo o resultado das inter-relações estabelecidas entre o espaço vivenciado (domínio das práticas), o espaço percebido (o domínio do conhecimento) e o espaço concebido (o domínio dos valores e das ideologias), traduzindo-se em diferentes formas de ruralidade. Ventura et al (2008, p. 155-158). 
tigação proposto não se esgota, no entanto, em uma mera descrição da multiplicidade e da heterogeneidade das trajetórias de desenvolvimento: é preciso compreender, também, em profundidade, o modo como "fatores externos" - incluindo aí a contra-urbanização, as mudanças climáticas e a globalização - influenciam o desenvolvimento das regiões rurais (Horlings e Marsden, 2010, p. 240).

Nos termos propostos por Ploeg e Marsden (2008) e demais pesquisadores envolvidos nesse programa de investigação, o desenvolvimento rural tem como foco, essencialmente, a revitalização e o fortalecimento do rural, bem como seu reposicionamento na sociedade como um todo (Ploeg et al, 2008, p. 3), o que implica em uma rearticulação dos processos, das atividades e das redes que constituem o rural. Mas, como observam os autores, o rural é composto por múltiplas estruturas. A rede rural é, nesse sentido, uma das muitas, e, freqüentemente, contraditórias estruturas (ou modos de organização) que operam nas regiões rurais e urbanas, podendo ser vista, portanto, como uma contra-estrutura, que busca romper com outras estruturas presentes, em um rural em transição.

\section{Possibilidades heurísticas da noção de rede no estudo das transformações do rural contemporâneo}

O itinerário percorrido até o momento nesta reflexão foi marcado, sobretudo, pelo esforço por compreender as distintas formas como a idéia de rede tem sido mobilizada como ferramenta na análise e interpretação das configurações do rural contemporâneo, a partir de diferentes correntes de interpretação. Coloca-se, então, a pergunta, talvez excessivamente pragmática: afinal, para que servem "as redes"? Em que medida, o recurso a essa noção pode contribuir em um esforço reflexivo de leitura e interpretação dos processos sociais, voltado à construção de 
futuros alternativos, em um ambiente em que a própria idéia de desenvolvimento vem sendo amplamente contestada? É possível encontrar um ponto de vista que permita superar o aparente impasse - estabelecido entre aqueles que acreditam na busca de um desenvolvimento alternativo, centrado nas pessoas e construído desde o local, e o esforço de desconstrução do desenvolvimento como narrativa, empreendido pelos pós-desenvolvimentistas em sua afirmação da singularidade e do local -, para a construção de um novo paradigma, em que a noção de desenvolvimento seja destituída de sua centralidade ${ }^{17}$ ?

Parte-se do pressuposto de que seria equivocado transformar "as redes" - seja como uma referência analítica seja como um conceito operacional - em um condensador de tantas promessas. Ao mesmo tempo, o exame das diferentes linhas de aproximação entre a noção de rede, os estudos agroalimentares e a análise dos processos de transformação do mundo rural, nos permite identificar uma série de potencialidades a serem exploradas, a partir de uma abordagem relacional dos atores, dos mercados, das políticas e dos processos sociais e ecológicos envolvidos na co-produção de distintas ruralidades. Mantendo o espírito inicial do texto, exploram-se, a seguir, alguns "núcleos de problematização", que foram identificados a partir desse esforço "transversal" de leitura dessas distintas vertentes de incorporação da noção de rede ao estudo das transformações do mundo rural na contemporaneidade.

Um primeiro elemento a ser destacado refere-se ao modo como os distintos enfoques anteriormente apresentadas abordam a questão da agência no âmbito das redes. A perspectiva de análise proposta pela ANT é, sem dúvida, a mais ousada nesse sentido, tendo como ponto de parti-

17 Um esforço consistente de crítica tanto ao desenvolvimento alternativo como às alternativas ao desenvolvimento, afirmadas pelos pós-desenvolvimentistas pode ser encontrado em Pieterse (1998). 
da uma percepção extremamente aberta tanto dos elementos como das conexões que constituem o Ator-Rede. Redes e atores só "ganham vida", de fato, através da reconstrução de determinadas cadeias de associações, bem como dos múltiplos processos de tradução que possibilitam a criação e, eventualmente, a estabilização, no tempo e no espaço, e sempre em caráter provisório, dos vínculos estabelecidos.

Essa definição performativa e semiótica do ator demarca diferenças importantes entre a ANT e outras abordagens relacionais que também buscam incorporar, como instrumento de análise, a noção de rede. Tanto na perspectiva orientada aos atores como na análise das redes sociais nos termos propostos por Granovetter, o social mantém o seu estatuto, ainda que de maneira distinta, como um campo específico de análise. Os vínculos estabelecidos no âmbito das redes constituem-se como interações entre indivíduos, famílias, comunidades ou organizações - os agentes não humanos operam fundamentalmente, aqui, como intermediários. No referencial de análise proposto por Granovetter, no entanto, parece existir uma ênfase muito grande na estrutura das redes, ou seja, no mapa dos vínculos estabelecidos, suas características (intensidade, freqüência, reciprocidade) e dinâmicas de transformação. Já, na perspectiva orientada ao ator, maior atenção é dada ao que Fuhse (2009) identifica como sendo as estruturas de sentido das redes sociais, consideradas como uma dimensão fundamental da análise, tendo em vista que as redes não são uma soma de relações sociais, mas, sim, uma estrutura (ou, talvez, uma configuração) de vínculos inter-relacionados (Fuhse, 2009, p. 62). A reflexividade das práticas, os processos de geração e intercâmbio de conhecimentos, bem como as distintas lógicas de apropriação e mobilização dos discursos em diferentes contextos de interação, são elementos fundamentais para que se possa melhor compreender as redes e os vários mundos que elas constituem. 
Um segundo núcleo de questionamentos diz respeito à articulação entre o material e o simbólico, o "humano" e o "não humano", no âmbito das redes, lembrando aqui que esses pares de elementos não são necessariamente equivalentes entre si. No caso da ANT, parte-se do princípio de simetria, ou seja, a natureza e a cultura, o social e o biológico, não se configuram, a priori, como níveis distintos de análise. $\mathrm{Na}$ abordagem integrada do desenvolvimento das regiões rurais, proposta por Ploeg, Marsden e demais pesquisadores integrados ao Programa ETUDE (Ploeg e Marsden, 2008; Horlings e Marsden, 2010), toma-se como ponto de partida a existência de um subsistema social e de um subsistema biológico (Ventura et al, 2008, p. 149-150), os quais, através de processos de co-produção e de co-evolução, interagem permanentemente na construção do "mundo rural". A própria idéia de sustentabilidade, referenciada por esses autores como dimensão teórica de análise, encontra-se ancorada em um reconhecimento da estreita imbricação existente entre processos ecológicos e processos sociais.

De modo geral, o que se identifica, nas distintas abordagens que buscam se utilizar da noção de rede no estudo dos processos de desenvolvimento rural, é uma crescente sensibilidade no que diz respeito às dimensões materiais (ecológicas, tecnológicas, corpóreas) envolvidas na configuração do rural. Refletindo, por exemplo, sobre o conceito de estrutura, Long (2007) propõe que a mesma seja conceituada como um amálgama heterogêneo de entidades "humanas", mas, também, "não humanas", as quais se tornam agentes "por delegação", reafirmando, ao mesmo tempo, as capacidades reflexivas e a criatividade dos atores sociais, em uma formulação capaz de permitir, ao que tudo indica, um diálogo bastante próximo com a perspectiva de redes própria da ANT, ainda que referenciada em uma visão distinta de agência. 
Um terceiro elemento de reflexão remete a uma análise das relações de poder que se estabelecem no âmbito das redes, suas dinâmicas de produção e reprodução e suas implicações na conformação e transformação das regiões rurais. Trata-se, nesse caso, de buscar compreender os distintos processos que possibilitam, de um lado, a imposição de determinados padrões e ordenamentos no âmbito das redes, e, de outro, a própria resistência a esses padrões.

Sugere-se, aqui, que o conceito de modos de organização, desenvolvido por Law (1994) e por outros autores, a partir da ANT (Murdoch, 1998), poderia contribuir, eventualmente, para uma melhor compreensão desses processos, captando os vários ordenamentos em disputa na produção e reprodução do mundo rural.

Segundo Law (1994, p. 94-114), os modos de organização não se confundem com o discurso e com os regimes de representação nos termos propostos por Foucault. Os ordenamentos em questão são recursivos e performativos, organizando material e simbolicamente a realidade, através de lógicas auto-reflexivas, que dão coerência ao mundo vivido pelos atores. Em muitas situações, como no laboratório estudado por Law, no livro 'Organizando a Modernidade' (Organizing Modernity) (Law, 1994), o que se impõe não é uma única forma de ordenamento, mas modos de organização em permanente interação. As dinâmicas inovadoras da rede rural, identificadas pelos pesquisadores do ETUDE como campos de relações capazes de ativar e fortalecer sinergias entre atores, recursos e práticas, numa perspectiva de sustentabilidade ${ }^{18}$ e de valorização do rural, coexistem com outros modos de organização, mobilizando cadeias de conexões que se estendem muito além do "local" ou do "espaço rural".

18 Reforça-se, aqui, que esse conceito (ou dimensão de análise), por seu conteúdo até certo ponto normativo, precisaria ser claramente estabelecido em sua relação com os diferentes contextos analisados. 
As questões aqui colocadas dialogam, ao que tudo indica, com a trajetória de reflexão percorrida pelos autores de Unfolding Webs e Networking the rural, quando apresentam a rede rural como uma contra-estrutura, que busca estabelecer uma ruptura com ordenamentos já existentes, criando novos padrões de coerência entre atividades, redes, recursos e atores (Marsden e Ploeg, 2008). A exemplo do que acontece com os modos de organização dominantes, essa contra-estrutura, como um campo de relações, não se esgota em uma mera revalorização do endógeno (em oposição a modelos ou recursos "vindos de fora"), ou do local (numa perspectiva defensiva), mobilizando um conjunto complexo de estratégias que se desdobram em diferentes níveis, envolvendo um crescente engajamento no que Swyngedouw (2004) chama de políticas de escala, ou seja, no esforço de construção, pelos diferentes atores, de novas configurações escalares, de forma a alterar as relações de poder envolvidas na apropriação e controle do espaço ou de posições consideradas estratégicas em um determinado circuito de conexões. $\mathrm{O}$ resgate desses processos de construção de alternatividades e de sua interação com modos dominantes de organização configura-se, sem dúvida, como uma dimensão importante a ser explorada na construção de uma abordagem relacional das transformações e transições do rural na contemporaneidade.

\section{Networks, actors and rural development: perspectives in the construction of a relational approach}

\section{Abstract}

The construction of a relational approach to the study of the complex social dynamics configuring the contemporary rural world stands, particularly after the 1980 's, as a challenge for the social sciences. In this direction, different lines of interpretation incorporated the notion of network, as an analytical tool connecting 
actors, meanings, objects and practices, in the study of rural development processes. This article aims to explore some of these analytical frames of reference, identifying convergences and discontinuities among different perspectives.

Keywords: Rural development. Networks. Relational approach. Actor-Network Theory.

\section{Referências}

ABRAMOVAY, Ricardo; MAGALHÃES, Reginaldo. O acesso dos agricultores familiares aos mercados de biodiesel: parcerias entre grandes empresas e movimento sociais. Texto aprovado para apresentação na CONFERÊNCIA DA ASSOCIAÇÃO INTERNACIONAL DE ECONOMIA ALIMENTAR E AGROINDUSTRIAL AIEA2, Londrina, jul. 2007). Disponível em: http://www.abramovay.pro.br/artigos_cientificos/2007/Biodiesel_AIEA2_Portugues.pdf. Acesso em: jan. de 2011.

AMÉRICA LATINA EN MOVIMIENTO. La agonia de um mitozComo reformular el desarollo?.Quito, América Latina en Movimiento, Ano XXXIII, II época, jun. 2009, $33 \mathrm{f}$.

BARNES, John A. Redes sociais e processo político. In: FELDMAN-BIANCO, Bela (org.). Antropologia das Sociedades Contemporâneas: Métodos. São Paulo: Editora Unesp, 2010. p. 171-204.

BOTT, Elizabeth. Família e rede social. Rio de Janeiro: Francisco Alves, 1976. $318 \mathrm{f}$.

BOOTH, David (org.) .Rethinking social develoment. Harlow: Longman Group Limited, 1994. $319 \mathrm{f}$.

CALLON, Michel . Actor-Network Theory: the Market Test. In: LAW, J.; HASSARD, J. (Eds.) Actor Network and After. Oxford and Keele: Blackwell and the Sociological Review, 1999.

CASTELLS, Manuel. A era da informação: economia, sociedade e cultura - A sociedade em rede. vol. 1. São Paulo: Paz e Terra, 1999.

COOPER, Frederick; PACKER, Randall. The history and politics of development knowledge. In: EDELMAN, M; HAUGERUD, A. (ed.). The Anthropology of development and globalization: from classical political economy to contemporary neoliberalism. Malden-USA/Oxford-UK/Carlton-Australia: Blackwell Publishing Ltd, 2005. p. 126-139. 
DICKENS, Peter et al. Chains and networks, territories and scales: towards a relational framework for analyzing the global economy. Global Networks, v. 1, n. 2, p. 89-112, 2001.

ELIAS, Norbert. Sociología fundamental. Barcelona: GEDISA, 1982. 216 p.

EMIRBAYER, Mustafa. Manifesto for a relational sociology. American Journal of Sociology, v. 103, n.2, sept. 1997, p. 281-317.

ESCOBAR, Arturo. Encountering development: the making and unmaking of the Third World. Princeton / New Jersey: Princeton University Press, 1995. 275 p.

ESCOBAR, Arturo. Imagining a post-development era. In: EDELMAN, M.; HAUGERUD, A. (ed.). The Anthropology of development and globalization: from classical political economy to contemporary neoliberalism. Malden-USA/OxfordUK/Carlton-Australia: Blackwell Publishing Ltd, 2005. p. 341-351.

ESCOBAR, Arturo. Una minga para el postdesarollo: lugar, medio ambiente y movimientos socials en las transformaciones globales. Lima: Programa Democracia y Transfomación Global / Univesidad Nacional Mayor de San Marcos, 2010. 222 p.

FLIEGSTEIN, Neil. Markets as politics: a political-cultural approach to market institutions. American Sociological Review, v. 61, p. 656-676, Aug. 1996.

FUHSE, Jan A. The meaning structure of social networks. Washington, Sociological Theory, v. 27, n. 1, p. 51-73, March, 2009.

GRANOVETTER, Mark. The strength of weak ties. The American Journal of Sociology, v. 78, n. 6, p. 1360-1380, May, 1973.

GRANOVETTER, Mark. Economic institutions as social constructions. Acta Sociologica, n. 35, p., 3-11, 1992.

GRANOVETTER, Mark. The impact of social structures on economic outcomes. Journal of Economic Perspectives, v. 19, n. 1, p. 33-50, winter, 2005.

HORLINGS, Ina; MARSDEN, Terry. The new rural paradigm and redefining the rural web. In: MILONE, Pierluigi; VENTURA, Flamínia. Networking the rural: the future of green regions in Europe. Assen-The Netherlands: Van Gorcum, 2010. p. 213-244.

LATOUR, Bruno. Reassembling the social: an introduction to Actor-NetworkTheory. Oxford / New York: Oxford University Press, 2007. 301 f.

LAW, John. Organizing modernity. Oxford (UK) and Cambridge (USA): Blackwell, 1994. $219 \mathrm{f}$.

LETONTURIER, Éric. Hermès - communication, cognition et politique, Paris, $\mathrm{n}$. 41, 2005, p. 41-50. 
LEYS, Colin. The rise and fall of development theory. Nairobi / London: EAEP / Jamer Currey, 1996. 205 p.

LONG, Norman. Sociologia del desarollo: una perspectiva centrada en el actor. San Luis de Potosí / México: El Colegio de San Luís / CIESAS, 2007a. 499 f.

LONG, Norman. Resistance, agency and counterwork: a theoretical positioning. In: WRIGHT, Wynne; MIDDENDORF, Gerard (eds). The fight over food: producers, consumers and activists challenge the global food system. Park-PA: The Pennsylvania State University Press, 2007.

LONG, N.; LONG, A. Battlefields of Knowledge: the interlocking of thory and practice in social research and development. London and New York: Routledge, 1992.

LONG, N.; PLOEG, J. D. van der. Demythologizing planned intervention: an actor perspective. Sociologia Ruralis, v. 29, n. 3-4, p. 226-249, Dec. 1989.

MIOR, Luiz Carlos. Agricultores familiares, agroindústrias e redes de desenvolvimento rural. Chapecó, SC: ARGOS, 2005.

MILONE, Pierluigi; VENTURA, Flamínia. Networking the rural: the future of green regions in Europe. Assen-The Netherlands: Van Gorcum, 2010.

MITCHELL, J. Clyde. Social Networks. Annual Review of Anthropology, v. 3, p. 279-299, 1974.

MURDOCH, Jonathan. Towards a geography of heterogeneous associations. Progress in Human Geography, v. 21, n. 3, p. 321-337, 1997.

MURDOCH, Jonathan. Networks - a new paradigm for rural development? Journal of Rural Studies, n. 16, p. 407-419, 2000.

PIETERSE, Jan Nederveen. Um paradigm or yours? Alternative Development, PostDevelopmente, Reflexive Development. Development and Change, Oxford/UK, v. 29, p. 342-373, 1998.

PIMBERT, Michel. Towards food sovereignty: reclaiming autonomous food systems. London: IIED, 2008.

PINHEIRO, Patrícia dos S. Saberes, plantas e caldas: a rede sociotécnica de produção agrícola de base ecológica no Sul do Rio Grande do Sul. 2010. Dissertação (Mestrado em Desenvolvimento Rural) - Programa de Pós-Graduação em Desenvolvimento Rural - PGDR, Universidade Federal do Rio Grande do Sul, Porto Alegre.

PLOEG, Jan Douwe van der. Labor, markets and agricultural production. Boulder-CO: Westview Press, 1990. 
PLOEG, Jan Douwe van der. Camponeses e impérios alimentares: lutas por autonomia e sustentabilidade na era da globalização. Porto Alegre: Editora UFRGS, 2008. PLOEG, Jan Dowe van der et al. Rural development: from practices and policies towards theory. Sociologia Ruralis, v. 40, n. 4, p. 391-408, Oct. 2000.

PLOEG, Jan Douwe van der; MARSDEN, Terry. Unfolding webs: the dynamics of regional rural development. Assen-The Netherlands: Van Gorcum, 2008.

POLANYI, Karl. A grande transformação: as origens da nossa época. Rio de Janeiro: Editora Campus, 2000.

RADCLIFFE-BROWN, A. R. Da Estrutura Social. In: Estrutura e Função nas Sociedades Primitivas. Lisboa: Edições 70, 1989, p.279-302. 336 p. RADOMSKY, Guilherme; SCHNEIDER, Sérgio. Nas teias da economia: o papel das redes sociais e da reciprocidade nos processos locais de desenvolvimento. Sociedade e Estado, Brasília, v. 22, n. 2, p. 249-284, mai.-agost. 2007.

SCHMITT, Claudia Job. Tecendo as redes de uma nova agricultura: um estudo socioambiental da Região Serrana do Rio Grande do Sul. 2001. 395 f. Tese (Doutorado em Sociologia) - Programa de Pós-Graduação em Sociologia, Instituto de Filosofia e Ciências Humanas, Universidade Federal do Rio Grande do Sul, Porto Alegre.

SCHNEIDER, Sérgio. A diversidade da agricultura familiar. Porto Alegre: Editora da UFRGS, 2006.

SCHNEIDER, Sérgio; NIEDERLE, Paulo A. Resistance strategies and diversification of rural livelihoods: the construction of autonomy among Brazilian family farmers. Journal of Peasant Studies, London, v. 37, n. 2, 2010. p. 379-405.

SCOTT, John. Social Network Analysis. A Handbook. London/Newbury Park / New Delhi: Sage Publications, 2000.

SIMMEL, Georg. Cuestiones fundamentales de sociologia. Barcelona: Editorial Gedisa S.A., 2002. 155 p.

SWEDBERG, Richard; GRANOVETTER, Mark. Introduction. In: GRANOVETTER, Mark; SWEDGERG, Richard (eds). The sociology of economic life. Princeton: Princeton University Press, 1992. p. 1-26.

SWYNGEDOUW, Erik. Globalisation or 'Glocalisation'? Networks, Territories and Rescaling. Cambridge-MA/USA, Cambridge Review of Internatinal Affairs, v. 17, n. 1, April 2004, p. 25-48.

VENTURA, Flamínia et al. The rural web: a synthesis. In: PLOEG, Jan Douwe van der; MARSDEN, Terry. Unfolding webs: the dynamics of regional rural development. Assen-The Netherlands: Van Gorcum, 2008. p. 149-174. 
WHATMORE, Sarah; THORNE, Lorraine. Nourishing networks: alternative geographies of food. In: GOODMAN, David; WATTS, Michael. Globalising food: agrarian questions and global restructuring. London and New York: Routledge, 1997. p. 287-303. p.287.

WILKINSON, John. A agricultura familiar ante o novo padrão de competitividade do sistema alimentar na América Latina, Estudos Sociedade e Agricultura, Rio de Janeiro, n.21.

WILKINSON, John. A teoria do Ator-Rede e economia política: do atrito à convergência via redes sociais, convenções, cadeias de valor global e redes de produção global. In: PORTO, Maria Stela Grossi; DWYER, Tom. Sociologia e realidade: pesquisa social no século XXI. Brasília: Editora Universidade de Brasília, 2006. p. 319-345.

WILKINSON, John. Redes, mercados e valores. Porto Alegre: Editora da UFRGS, 2008.

WILKIS, Ariel; BERGER, Matías. La relación individuo-sociedad: una aproximación desde la sociología de Georg Simmel. Athenea Digital - Revista de pensamiento y investigación social, Bellaterra/España; n. 4, p. 77-86, primavera de 2005.

Recebido: $23 / 02 / 2011$

Aceite final: 07/04/2011 
